\title{
WEIGHTED SINGULAR-VALUED DECOMPOSITION OF MATRICES AND METHODS OF SOLVING PROBLEMS WEIGHTED PSEUDOINVERSE WITH SINGULAR WEIGHTS
}

Weighted pseudoinverse matrices with singular weights and their expansions into matrix power series and matrix power products are obtained based on weighted singular-valued decomposition of matrices with singular weights. Boundary representations of weighted pseudoinverse matrices with singular weights are obtained. Regularization methods for the calculation of weighted normal pseudosolutions with singular weights are constructed and investigated.

Key words: weighted singular-valued decomposition of matrices with singular weights, weighted pseudoinverse of matrices.

Одержано 31.02.2019

UDC 330.341

DOI: $10.32626 / 2308-5878.2019-19.17-21$

J.-F. Emmenegger, Dr.,

D. Chable, Dipl. math.,

H. A. Nour Eldin, Prof. Dr.,

H. Knolle, Dr. math.

University of Fribourg, Switzerland

\section{SRAFFA AND LEONTIEF REVISITED. MATHEMATICAL METHODS AND MODELS OF A CIRCULAR ECONOMY (BOOK PRESENTATION)}

The main purpose of the present book is to reveal, elucidate and illustrate the mathematical background of Sraffa's theory didactically in detail with the means of modern matrix algebra and the corresponding fundamental theorems. Our book is also a contribution to the increasing call for alternative approaches to the understanding of the realities of today economic activity.

Key words: economics, productive Leontief model, Frobenius number.

Economics ${ }^{1}$ is a decision-based and number-based science.

"Currency and market decisions in a decision-based economy» [1]

"All what we are doing should be based theoretically».

Andrei Broder, scientist, Google ( 2017)

1 The Webster New Collegiate Dictionary, p. 260, defines the term «Economics» as follows: "The science that investigates the conditions and laws affecting the production, distribution and consumption of wealth, or material means of satisfying human desires; political economy». 
Preliminary Remarks. This book focuses mainly on Sraffa's theoretical model Production of Commodities by Means of Commodities ([2], PCMC, 1960). It interprets and extends PCMC following the initial footsteps undertaken by Newman, Pasinetti and especially Schefold in the German version of PCMC [3]. Matrix algebra is used applying the mathematical and notational standards set By Miller and Blair [4] and the standards defined by EUROSTAT [5]. The dominating importance of the Perron-Frobenius Theorem, ensuring the existence of a solution to Sraffa's model of production, reformulated as an eigenvalue problem, is stressed, together with an important result due to Ashmanov's book ([6], Theorem 1.5, p. 3)] concerning Leontief models, productive Leontief models and their Frobenius number. These techniques are supplemented by elements of graph theory.

Piero Sraffa (1898-1983), a classical economist, reformulated in his book Production of Commodities by Means of Commodities (PCMC) «the theory of value and distribution». Wassili Leontief (1906-1999) [7] made early contributions to input-output analysis and earned the Nobel Prize in Economics in 1973. Sraffa and Leontief are concerned with the whole structure of production, considered in its totality as a cyclic process. A matrix describes quantitatively the exchange between the branches of the economy.

On less than 100 pages Sraffa uses in PCMC mathematical concepts and theorems which he has mainly hidden. He just presents calculus and numerical results. The main purpose of the present book is to reveal, elucidate and illustrate the mathematical background of Sraffa's theory didactically in detail with the means of modern matrix algebra and the corresponding fundamental theorems. A large place is given for computed examples.

Our book is also a contribution to the increasing call for alternative approaches to the understanding of the realities of today economic activity. In writing this book we have stood on the shoulders of eminent Sraffa connoisseurs: P. Newman, 1962; B. Schefold, 1976 and, 1989; L. L. Pasinetti, 1977, 1980 and (1986); H. D. Kurz and N. Salvadori [8], 2007; A. Roncaglia, 2009.

Wassili Leontief (1906-1999) models the economic activity within the context of a circular economy of production and exchange, today expressed in Input-Output Tables in monetary terms. Leontief proposed to divide the economy into sectors, each one producing a group of products. There is a highly technical process to achieve this partition described by the NACE Rev. 2 report [9], and the CAP nomenclature, leading to InputOutput Tables and Input-Output Analysis, see the European Union [5].

Independently of Leontief, Sraffa in PCMC [2], linearly modeled the English production of single commodities, like wheat, iron or pigs, considering the circularity of these production processes expressed in physical terms. He solved the distribution problem of David Ricardo (1772-1823), determined the production prices and the labour values. Sraffa's and Leontief's approach both need matrix algebra and the fundamental theorem of Frobenius [10]. 
Summary of the Chapters. This summary begins with the second chapter, the first one being the Introduction.

Chapter 2 gives a rigorous, detailed and ahead presentation of the set of matrices and vectors used in Input-Output Analysis. The notations and matrix algebra involved permit an advanced presentation of the material. The elements of the Leontief Input-Output Tables (IOT) are then presented. The principles of the system of Classification of products by activities (CAP), respectively the Nomenclature des activits économiques dans la communauté européenne (NACE) are explained. They are at the basis of the determination of the homogenous branches, constituting the IOTs. A selection of Leontief Input-Ouput models are presented.

Chapter 3 is a complete discussion of the three elementary examples figuring at the beginning of PCMC, described now in terms of matrix algebra and introducing the Perron-Frobenius Theorem [10] as the centre piece of the algebraic structure of Sraffa's models.

Chapter 4 develops the complete theory of Sraffa's price model for single commodity production processes, examining in particular the distinction between basic and non-basic commodities. Examples are calculated, determining all involved economic variables and economic ratios.

Novelties: the general relationship between the rate of profits, the surplus ratio and the ratio of total wages to national income, valid for all Sraffa systems; the introduction of directed graphs and bipartite networks as tools for the analysis of all types of Sraffa production processes.

Chapter 5 presents the complete theory of the Standard system of production for single commodity processes, including the famous linear relationship between the rate of profits, the Standard ratio and the share of total wages to national income, valid for all Standard systems.

Novelties: explicit formulation of the fundamental relations forming the basis of a Standard system; the introduction of the notion of the commodity space and the orthogonal Euler mapping (Euler affinity) central for the transformation of an actual non standard System into a Standard system.

Chapter $\mathbf{6}$ is an introduction to joint production systems, where the same commodities may be produced by more than one industry.

Novelties: output polyhedrons; a compact algebraic methodology for the distinction between basic and non-basic commodities which completes the approaches of Manara-Pasinetti-Schefold to the case of joint production systems; a matrix introduced by Pasinetti [11] shows to be pertinent to determine the number of basics.

Chapter 7. This chapter has been proposed and developed by H. Knolle.

Joint production systems are considered with industries producing in parallel several commodities, a typical situation with ecological conse- 
quences. Then, new approaches and examples treating waste problems and presenting situations involving ecological economics and taxation are treated. The main proposition is to show that Sraffa's price model offers an approach to treat ecological problem, involving waste in the whole economic system. The consequences on the prices are studied.

Chapter 8 is entirely concentrated to novel extensions of Sraffa's price models as indicated in the corresponding item of the Table of Contents.

Chapter 9 is a complete formal algebraic analysis of the interindustrial economy, developed by H. A. Nour Eldin. Tables of matrices presenting synoptically the aspect of value, quantities, prices and objects of Leontief's and Sraffa's concepts. It cumulates in the statement that the Interindustrial Market together with the Consumption Market is unified to the Leontief-Sraffa economy. Each one of these three entities is described by a proper sets of matrices and vectors.

Chapter 10 goes beyond simplified educational examples and gives a presentation of how Sraffa's approach, together with the IOT apparatus, can be applied to official IOTs. In this case we apply the developed methodology to the official Swiss IOTs 2008 and 2014 and the German IOT 2013. We also compute the productiveness of these economies. We perform some aggregations of the official IOTs and show the limits of these calculations.

Chapter 11 summarises the results obtained in this book and indicates proposed avenues of research in an extended Sraffa context.

Chapter 12 (Appendix I) contains all the necessary mathematical tools required for a complete understanding of the present text.

Chapter 13 (Appendix II) is a summary of Schefold's historical contribution to the understanding of Sraffa's PCMC.

Chapter 14 Glossary of terms.

Acknowledgments go to the publishing House de GruyterOldenbourg and the encouraging and professional support of Mrs. Kristin Berber-Nerlinger, lecturer, and Mrs. Nadja Schedensack, technical support, then to the artist Karim Noureldin, who permitted to use his splendid artwork for the cover of the book. Without the competent organizational work accomplished by Tamara Bardadym, encouraging and animating the colleagues of the Kiev group, our book could not have been written. Tamara Bardadym contributed to the book with competent proof-reading of the Lemmas, Theorems and the proofs.

\section{References:}

1. Nour Eldin, H. A., Emmenegger, J.-F., Nabout, A. A. Currency and Market Decisions. Decesion-Based Economy. 2019.

2. Sraffa P. Warenproduktion mittels Waren (aus dem Englischen ubersetzt mit einem Anhang von B. Schefold), Edition Suhrkamp 780, Erste Auage. 1976. 
3. Miller R. E., Blair P. D. Input-Output Analysis, Foundations and Extensions. Cambridge University Press, 2nd edition. 2009.

4. Carré H. NACE Rev. 2, Statistical classification of economic activities in the European Community. General and regional statistics, Methodologies and working papers, European Community. 2008.

5. Norlund L. Eurostat Manual of Supply, Use and Input-Output Tables. Luxembourg: Office for Official Publications of the European Community. 2008.

6. Ashmanov S. A. Introduction in Mathematical Economics (in Russian language). Moscow : Nauka, 1984. 296 p.

7. Leontief W. W. Die Wirtschaft als Kreislauf. Archiv für Sozialwissenschaft und Sozialpolitik. 1928. Vol. 60. P. 577-623.

8. Sraffa P. Production of Commodities by means of Commodities. Cambridge : Cambridge University Press. 1960.

9. Kurz H. D., Salvadori N. Theory of Production. A Long-Period Analysis. Cambridge University Press, paperback. 1995. 2007.

10. Frobenius G. Über Matrizen aus nicht negativen Elementen. Berliner Bericht. 1912. P. 456-477.

11. Pasinetti L. L. (ed.). Essays on the Theory of Joint Production. New York : Columbia Univ. Press 1980.

\section{СРАФФА И ЛЕОНТЬЕВ. ПЕРЕСМОТР. МАТЕМАТИЧЕСКИЕ МЕТОДЫ И МОДЕЛИ КРУГОВОЙ ЭКОНОМИКИ (ПРЕЗЕНТАЦИЯ КНИГИ)}

Основная цель настоящей книги - детально раскрыть, прояснить и проиллюстрировать математическое обоснование теории Сраффы с помощью современной теории матриц и соответствующих фундаментальных теорем. Наша книга также является ответом на появившийся запрос на альтернативные подходы к пониманию реалий современной экономической деятельности.

Ключевые слова: экономика, продуктивная модель Леонтьева, число Фробениуса.

Date received 12.03.2019 